\title{
EVALUATION OF BREAD WHEAT GENOTYPES USING SELECTION INDEX
}

\author{
Mohammed Ali Hussain, Rezgar Idrees Saeed, Hajer S.A. Askandar \\ and ABbas Alo KHETHer \\ Dept. of field crops, College of Agricultural Engineering Sciences, University of Duhok, \\ Kurdistan Region - Iraq
}

(Accepted for Publication: October 21, 2019)

\begin{abstract}
Experiment was carried out at farm of Field Crop Department, College of Agriculture, University of Duhok. Twelve genotypes of bread wheat were sowing in 25/11/2017 to construct selection indices using Randomize Complete Block Design (RCBD) with three replications.

The experiment included six traits studied were plant height $(\mathrm{cm})$, flag leaf area $\left(\mathrm{cm}^{2}\right)$, No. of grains spike${ }^{1}$, weight of seed spike ${ }^{-1}, 1000$-grain weight $(\mathrm{gm})$ and grain yield row $^{-1}(\mathrm{gm})$. The results showed the analysis of variance for six traits was highly significant for plant height, No. of grain spike ${ }^{-1}$, weight of grains spike, 1000grain weight and non-significant for flag leaf area. Although the results revealed the combined analysis were highly significant difference for all traits except No. of grain spike ${ }^{-1}$ and weight of grain spike ${ }^{-1}$. Also, the results exhibited the best selection index was (L146) which include the traits (grain yield, plant height, 1000grain weight) and giving relative efficiency $7-29 \%$. Of selection of yield alone. The GCV was medium for all traits and low for flag leaf area while, the PCV was medium for plant height, weight grain spike $^{-1}$, No. of grain spike ${ }^{-1}$ and 1000 -grain weight, whereas, high for grain yield and low for flag leaf area. Concurring the genetic advance as mean (GAM) the results showed the high value for number of grain spike ${ }^{-1}$ and weight of grain spike $^{-1}$ and medium for plant height, 1000-grain weight, grain yield and low for flag leaf area, the value ranged between 5.07 to $20.47 \%$. The heritability was high for all traits and medium for flag leaf area. The results indicated highly significant difference between the wheat genotype in the value of selection index for these which computed depend on the better selection index, grain yield, plant height and 1000-grain weight.

Form this study that the better for genotypes was Abu- graib-1, Research-4, IPA-99 and Sham-6, over all genotypes and could be used this genotypes in breeding program to improve yield of wheat and develop new variety with good productivity and good quality performance to Kurdistan and Iraqi environments.
\end{abstract}

KEY WORD. Wheat genotypes, yield, yield components, selection index.

https://doi.org/10.26682/cajuod.2020.22.2.16

\section{INTRODUCTION}

I ndex selection is one of the fundamentals method for the genetic improvement of traits in crop plants. A theory, which introduced independently by Smith 1936 in plant and Hazel index and has be demonstrated to be more reliable than independent culling level (ICI) and tandem selection(TS) methods in terms of maximizing genetic gain in a crop population. Hazel and Lush,(1942); Cotterill, (1985) and Costal et al.,(2008) reported that this approaches the most effective as compared with (ICI ) and tandem (TC) selection methods for independent traits while, having at least the same efficiency in the case of correlated traits. Smith(1936) indicated that the mainly due to their advantage of talking in to account of heritability, the interrelation ship of traits using genetic and phenotypic correlation and the economic values of traits selection for an index which give proper weight to each traits is more efficient than selection for one traits or for several traits independently. Hazel 1943 in animals and Lemer et al., (1947) reported that the method for estimating optimum relative weight for different selection projects, while, Robinson et. al.,(1951) have given procedures for estimating genotypic and phenotypic covariance required for construction of a selection index.

Several researchers have been carried the selection indexes in wheat and some other selffertilized crops has been given by (Pesek and Baker, 1969; Singh etal., 1979; Bhathagar et al., 
1982; Wells and Kofoid,1986; Ali,1995; Ahmad and Hamdoo, 2000; Al Guborly et al , 2006; Dawod et al., (2010). The objective of this study to construct several selection indices among six traits of wheat and to compare their efficiency with that from direct selection from grain yield and yield components in order to find a simple and useful index to be used in the evolution of twelve wheat genotypes.

\section{MATERIALS AND METHODS}

The genetic material used in this study were twelve genotypes of bread wheat Table 1 . The all genotypes were planting in 25/11/2017 at the field of College of Agriculture , Duhok University, using Randomized Complete Block Design (RCBD) with three replications, each plot contained three rows, 3 meter long and $0.25 \mathrm{~m}$ apart with seeding rate $140 \mathrm{~kg} / \mathrm{ha}^{-1}$.

Table (1): Genotypes using in the experiment

\begin{tabular}{lll}
\hline No & Name & Source \\
\hline 1. & Resarch-4 & Central of Agriculture Research Duhok \\
\hline 2. & Abu-garib-1 & Central of Agriculture Research Abu-graib \\
\hline 3. & IPA-99 & IPA \\
\hline 4. & Sham-6 & Central of Agriculture Research Duhok \\
\hline 5. & TAWAHI-3 & International center of Agriculture Research in Dry Area \\
\hline 6. & Makipak & Central of Agriculture Research Duhok \\
\hline 7. & BABAGA-3 & Internal center of Agriculture Research in Dry Area \\
\hline 8. & D-7 & Central of Agriculture Research Abu-graib \\
\hline 9. & Azadi & Centeral of Agriculture Recearch. \\
\hline 10. & IPA-95 & IPA \\
\hline 11. & SETTAR-85 & Internatioal center of Agriculture Research in Dry Area \\
\hline 12. & Tamoze-2 & Central of Agriculture Research Duhok \\
\hline
\end{tabular}

The field plants was irrigated after planting by sprinkler for about six hours only and then depended upon natural precipitation (the amount of rain for seven months (December /2017, January, February, march, April, and may/ 2018) were in Table

Table (2): The rainfall for seven month 2017-2018.

\begin{tabular}{|c|c|c|c|c|c|}
\hline \multirow[t]{2}{*}{ Date } & \multirow[t]{2}{*}{ Month } & \multicolumn{2}{|c|}{ Heat } & \multirow[t]{2}{*}{ Humidity } & \multirow[t]{2}{*}{ Rain } \\
\hline & & max. & $\min$. & & \\
\hline \multirow[t]{2}{*}{2017} & November & 20.76 & 7.92 & 62.37 & 27.8 \\
\hline & December & 56.29 & 4.835 & 61.17 & 9.4 \\
\hline \multirow[t]{5}{*}{2018} & January & 13.86 & 4.158 & 70.85 & 73.6 \\
\hline & February & 16.2 & 5.525 & 74.32 & 66.4 \\
\hline & March & 22.63 & 9.871 & 59.01 & 16 \\
\hline & April & 26.47 & 11.78 & 55.4 & 103.5 \\
\hline & May & 30.93 & 17.55 & 52.6 & 85.6 \\
\hline
\end{tabular}

Abu- graib-1, Research-4, IPA-99 and Sham- 
Fertilizer were applied at rate of $400 \mathrm{~kg} / \mathrm{ha}-1$ of Npk (18.30,0 before planting and nitrogen as area at the rate of $200 \mathrm{~kg} / \mathrm{h}$. applied at tiller stage and herbicide (pallas) used to control narrow and broad leave weeds at rate of 450 to $500 \mathrm{ml} / \mathrm{ha}$ at the stage of 3-4 Leaves. The studied traits were plant height $\mathrm{cm}$, Leaf area $\mathrm{cm} 2$, number of grains spike-1, spike seed weight, 1000 - grain weight and grain yield. Analysis of variance was carried out according to (Gomez and Gomez, 1984) the estimates of phenotypic and genotypic variances (VP and VG ) were obtained by using expected mean square form analysis of variance, the following estimators were calculated.

1. Broad sense heritability $(\mathrm{H} 2)$ from the ratio of VG and VP

2. Expected genetic advance GA:

$\mathrm{GA}=\mathrm{K}(\mathrm{H} 2)(\sqrt{\mathrm{VP}})$ where $\mathrm{k}=$

Selection differential in standard units and equal 1.75 for $10 \%$ selected

$(\sqrt{\mathrm{VP}})=$ phenotypic standard deviation and expected genetic advances as

percent of trait mean y.. estimated from equation,

$\mathrm{GA}=(\mathrm{GA}) /(\mathrm{Y} ..) \mathrm{X} 100$ (Assefa et al.,2011).

3. The method of constructing the selection indicates were those as outlined by Miller et al.,
1958 which maximize yield the selection index will be of the form

$1=\mathrm{b} 1 \mathrm{x} 1+\mathrm{b} 2 \mathrm{x} 2 \ldots+\mathrm{b}$ xn where $\mathrm{x} 1, \mathrm{x} 2 \ldots \mathrm{xn}$ are the phenotypic values of the traits and $b 1, b 2 . . . b n$ are the relative weights to be applied to each trait, and (b) values obtained from metrix notation as follows $b=p-1 g$, where $p-1$ The inverse of the phenotypic variance- covariance matrix, $g(g$ 1y,g 2 y.....gny)the genotypic covariance of each of the observed characters with yield. The expected genetic advance when selection is based on the selection indices

$\mathrm{GA}=\mathrm{K} \sqrt{ } \mathrm{b} 1 \operatorname{cov} \mathrm{g} 1 \mathrm{y}+\mathrm{b} 2 \operatorname{cov} \mathrm{g} 2 \mathrm{y}+\ldots . . .+\mathrm{bngy}$

4. Selection indices values from each genotype is each replicate were estimated using the more efficient selection index, then analysis variance carried out from these values, and comparison between the genotypes means by Dancans Multiple Range Test (DMRT).

\section{RESULTS AND DISCUSSIONS}

Table 3. Showed the analysis of variance for six characters of broad wheat genotypes according to Randomized Complete Block Design method. It was revealed that genotypes mean square was highly significant for all characters except flag leaf area.

Table (3): Analysis of variance for characters of bread wheat genotypes.

\begin{tabular}{|c|c|c|c|c|c|c|c|}
\hline \multirow[t]{3}{*}{ S.o.v. } & \multirow[t]{3}{*}{ d.f } & \multicolumn{6}{|c|}{ M.S. } \\
\hline & & \multicolumn{6}{|c|}{ Characters } \\
\hline & & $\begin{array}{c}\text { Plant height } \\
\mathrm{cm}\end{array}$ & $\begin{array}{l}\text { Flag leaf } \\
\text { area cm2 }\end{array}$ & $\begin{array}{c}\text { No. grains spike } \\
-1\end{array}$ & $\begin{array}{c}\text { weight of } \\
\text { grain spike - } \\
1 \mathrm{~g} \\
\end{array}$ & $\begin{array}{l}1000 \text { grain } \\
\text { weight } g\end{array}$ & $\begin{array}{c}\text { Grain yield row- } \\
1(\mathrm{~g})\end{array}$ \\
\hline Replications & 2 & 9.41 & 21.63 & 49.95 & 0.03 & 13.19 & 3498.18 \\
\hline Genotypes & 11 & 202.56 ** & $25.72 \mathrm{~ns}$ & $173.00^{* *}$ & $0.33^{* *}$ & $83.36^{* *}$ & $6633.61^{* *}$ \\
\hline Error & 22 & 19.91 & 9.45 & 14.70 & 0.04 & 8.70 & 1874.56 \\
\hline Total & 35 & & & & & & \\
\hline
\end{tabular}

The mean performance of genotypes for all characters was presented in Table 4. For plant height the results in the same table exhibited, the highest value was recorded by genotypes 9 which were $(87.43 \mathrm{~cm})$ and the lowest value was $(57.81$ $\mathrm{cm})$ was obtained by genotype 3. For flag leaf area, the genotypes (1) had the largest leaf area $(53.28 \mathrm{~cm} 2)$ while, the smallest value $(44.17 \mathrm{~cm} 2)$ recorded by genotype 5 . Also, in the same table the maximum number of grain spike-1 (66.88) was noticed in genotypes 12 whereas, the genotypes 5 gave the minimum number of grain spike- 1 which was 47.46. Regarding to weight of grain spike, genotype 12 showed highest value (2.78) while the genotype 9 had the lowest value (1.63). For 1000grain weight, the genotypes 7 recorded the maximum value $(52.33 \mathrm{~g})$ while, the genotypes 3 exhibited the minimum value $(34.07 \mathrm{~g})$. In traits grain yield row the genotypes (1) and (2) was superiority over all genotypes giving $302.60 \mathrm{gm}$ and $299.33 \mathrm{~g}$ respectively while, the genotype 12 gave the lowest value $168.13 \mathrm{~g}$. From the results 
above the genotype (1) had maximum leaf area and the flag leaf plays a very important role in grain filling in small grain crops such as wheat because of its position on the column. It is the top most leaf and as such it intercepts quite a lot of radiation. Assimilation translocation from the flag leaf (source) to the panicle (reproduction sink) is enhanced by proximity of the flag leaf to the sink. When the flag leaf of a small grain cereal crop is lost or destroyed, grain yield is lost as a result. Many researchers pointed to some results such as Bhathagar et. al., 1982 and wells and Kofoid, 1986.

Table (4): Means for characters of bread wheat genotypes.

\begin{tabular}{|c|c|c|c|c|c|c|}
\hline \multirow[t]{3}{*}{ Genotypes } & \multicolumn{5}{|c|}{ Mean } & \multirow[b]{3}{*}{ Grain yield row- 1} \\
\hline & \multicolumn{5}{|c|}{ Characters } & \\
\hline & Plant height $\mathrm{cm}$ & $\begin{array}{c}\text { Flag leaf area } \\
\mathrm{cm} 2\end{array}$ & No. grains spike -1 & $\begin{array}{c}\text { weight of grain } \\
\text { spike }-1 \mathrm{~g}\end{array}$ & $\begin{array}{c}1000 \text { grain weight } \\
\mathrm{g}\end{array}$ & \\
\hline 1. & $70.10 \mathrm{~cd}$ & $53.28 \mathrm{a}$ & $55.70 \mathrm{bcd}$ & $2.31 \mathrm{bcd}$ & $41.55 \mathrm{c}$ & $302.60 \mathrm{a}$ \\
\hline 2 & $75.60 \mathrm{bc}$ & $48.97 \mathrm{abc}$ & $62.57 \mathrm{ab}$ & 2.18 cde & $34.89 \mathrm{de}$ & $299.33 \mathrm{a}$ \\
\hline 3 & $57.81 \mathrm{e}$ & $50.21 \mathrm{ab}$ & $57.32 \mathrm{bc}$ & $1.94 \mathrm{def}$ & $34.07 \mathrm{e}$ & $250.23 \mathrm{abcd}$ \\
\hline 5 & $68.83 \mathrm{~cd}$ & $44.17 \mathrm{c}$ & $47.46 \mathrm{e}$ & $2.24 \mathrm{bcd}$ & $47.26 \mathrm{~b}$ & $223.00 \mathrm{abcd}$ \\
\hline 6 & $81.36 a b$ & $52.25 \mathrm{a}$ & $54.86 \mathrm{~cd}$ & $2.38 \mathrm{abc}$ & $43.39 \mathrm{bc}$ & $170.00 \mathrm{~d}$ \\
\hline 7 & $72.05 \mathrm{~cd}$ & $47.88 \mathrm{abc}$ & $50.12 \mathrm{de}$ & $2.62 \mathrm{ab}$ & $52.33 \mathrm{a}$ & $223.53 \mathrm{abcd}$ \\
\hline 8 & $63.58 \mathrm{de}$ & $49.21 \mathrm{abc}$ & $61.03 a b c$ & $2.44 \mathrm{abc}$ & $40.04 \mathrm{~cd}$ & $268.53 a b$ \\
\hline 9 & $87.43 \mathrm{a}$ & $49.12 \mathrm{abc}$ & $40.23 \mathrm{f}$ & $1.63 \mathrm{f}$ & $40.68 \mathrm{c}$ & $172.23 \mathrm{~cd}$ \\
\hline 10 & $76.55 \mathrm{bc}$ & $45.92 \mathrm{bc}$ & $60.30 \mathrm{abc}$ & $2.12 \mathrm{cde}$ & $35.18 \mathrm{de}$ & $258.17 a b$ \\
\hline
\end{tabular}

Means bearing different letters within each column differ significantly at p.0.05.

Table 5. Showed the combine analysis for characters of bread wheat genotypes. In this table used six characters in selection index in all possibility. The results in the same table exhibited highly significant difference for all characters except traits (No. of grain spike-1 and weight of grain spike-1) when using traits or more characters. To constructed of selection index, the results exhibited, the choice of different Striates was necessary to pick the index having fewer traits with better grain. Similar results were obtained by other researchers Alguborly et al., 2006, Dawod et al., 2010, Zine et al., 2018.

Table (5): Combined analysis for characters of bread wheat genotypes

\begin{tabular}{|c|c|c|c|c|c|c|c|c|c|}
\hline \multirow[t]{3}{*}{ S.0.V } & \multirow[t]{3}{*}{ d.f } & \multicolumn{8}{|c|}{ M S } \\
\hline & & \multicolumn{8}{|c|}{ Characters } \\
\hline & & $1 \times 2$ & $1 \times 3$ & $1 \times 4$ & $1 \times 5$ & $1 \times 6$ & $2 \times 3$ & $2 \times 4$ & $2 \times 5$ \\
\hline Rep. & 2 & 54.57 & 23.39 & 22.17 & 58.10 & 3210.66 & 102.73 & 52.21 & 18.02 \\
\hline Genotype & 11 & $185.92^{\star *}$ & $259.97^{\star *}$ & $24.81^{*}$ & $94.80^{\star *}$ & $6899.77^{\star *}$ & $208.50^{\star *}$ & $182.66^{\star \star}$ & $168.84^{* *}$ \\
\hline Error & 22 & 21.56 & 41.38 & 9.52 & 20.71 & 1974.30 & 52.19 & 16.09 & 26.06 \\
\hline Total & 35 & & & & & & & & \\
\hline
\end{tabular}




\begin{tabular}{lllllll}
\hline $\mathbf{2 \times 6}$ & $\mathbf{3 \times 4}$ & $\mathbf{3 \times 5}$ & $\mathbf{3 \times 6}$ & $\mathbf{4 \times 5}$ & $\mathbf{4 \times 6}$ & $\mathbf{5 \times 6}$ \\
\hline 4367.79 & 10.40 & 2.91 & 3851.54 & 12.56 & 3511.98 & 3087.30 \\
\hline $7336.59^{* *}$ & $197.54^{* *}$ & $314.03^{* *}$ & $6092.67 \mathrm{~ns}$ & $89.05^{\star *}$ & $6620.77^{* *}$ & $6117.29^{*}$ \\
\hline 2001.78 & 20.88 & 31.61 & 2096.19 & 9.63 & 1882.44 & 1957.82 \\
\hline
\end{tabular}

based on the various selection index and genetic efficiencies over direct selection for yield and six of these tested indices are presented in Table 6. The predictive genetic advanced in yield 4 indices at $10 \%$ selection intensity range from 7.892 to 32.5 as compared with a predictive advanced of 7.89 for direct selection on yield. The predicted selection grain in efficiency from use of the indices range from 25.63089 to 107.2943 for flag leaf area and leaf area with 1000- grain weight. From the results in the same table, the best selection index was L1.46 (which include the grain weight, giving relative efficiency of $7.29 \%$ of the selection of yield alone. Therefore, this index was adopted in the differentiation between wheat genotypes.

$[$ L146 $=0.168$ (grain yield)- 0.2569 (plant height-399) (1000- grain weight)] and followed in importance the index L 2345, L 2345, L 345, L 465, L 2346, L 346 and L 1245, the indices and at last, it is noted that all the indices which empty of the yield trait were less efficient than the selection for a yield alone

\begin{tabular}{|c|c|c|c|c|c|c|c|c|}
\hline Index & GA & Efficiency & Index & GA & efficiency & Index & GA & efficiency \\
\hline I1 & 30.79471 & $100 \%$ & $\mathrm{I} 123$ & 30.81365 & 100.0615 & $\mathrm{I} 12$ & 31.18572 & 101.2697 \\
\hline I123456 & 32.91425 & 106.8828 & I124 & 31.48977 & 102.2571 & $\mathrm{I} 13$ & 30.80007 & 100.0174 \\
\hline I12346 & 32.54803 & 105.6936 & I126 & 31.43497 & 102.0791 & $\mathrm{I} 15$ & 31.08497 & 100.9426 \\
\hline I12356 & 31.48626 & 102.2457 & I134 & 31.54546 & 102.0962 & I16 & 31.40722 & 101.989 \\
\hline $\mathrm{I} 23456$ & 30.77444 & 99.93418 & $\mathrm{I} 145$ & 32.45211 & 105.3821 & $\mathrm{I} 25$ & 10.12143 & 32.86743 \\
\hline I1234 & 31.57122 & 102.5216 & I146 & 33.04096 & 107.2943 & $\mathrm{I} 26$ & 18.2465 & 59.25206 \\
\hline I1235 & 31.48569 & 102.2438 & I156 & 31.44022 & 102.0962 & $\mathrm{I} 34$ & 17.08294 & 55.47362 \\
\hline I1236 & 31.47936 & 102.2233 & $\mathrm{I} 234$ & 20.74147 & 67.354 & $\mathrm{I} 35$ & 19.8848 & 64.57213 \\
\hline $\mathrm{I} 2345$ & 27.20532 & 88.34413 & I 246 & 25.72787 & 83.54639 & I56 & 19.00968 & 61.73034 \\
\hline $\mathrm{I} 2346$ & 26.43373 & 85.83854 & $\mathrm{I} 256$ & 19.60678 & 63.66931 & & & \\
\hline $\mathrm{I} 2456$ & 26.7544 & 86.87986 & $\mathrm{I} 345$ & 26.0057 & 84.4486 & & & \\
\hline I1245 & 32.46946 & 105.4384 & $\mathrm{I} 346$ & 25.19878 & 81.82828 & & & \\
\hline I1246 & 32.15719 & 104.4244 & $\mathrm{I} 356$ & 22.66044 & 73.5855 & & & \\
\hline I1256 & 31.48135 & 102.2297 & $\mathrm{I} 456$ & 25.53236 & 82.91151 & & & \\
\hline I1356 & 31.4584 & 102.1552 & & & & & & \\
\hline $\mathrm{I} 2356$ & 23.63642 & 76.75481 & & & & & & \\
\hline I3456 & 28.95658 & 94.03102 & & & & & & \\
\hline I2 & 7.892958 & 25.63089 & & & & & & \\
\hline
\end{tabular}


characters, and low for flag leaf area. While, the pcv was medium for plant hight, weight of grain spike-1, number of grain spike-1 and 1000- grain weight whereas, was high for grain yield and low for flag leaf area.

Regarding to heritability was high for all characters and medium for flag leaf area and grain yield. The results in the same table showed GAMY. Was high for weight grain spike-1 and number of grain spike-1 and medium for plant height, 1000-grain weight and grain yield and low for flag leaf area. The weight grain spike-1 and number of grain spike-1 exhibited high broad sense heritability and associated with high genetic advance as mean. From this results can be useful of these characters to improving the yield in bread wheat after putting in program of wheat breeding. These results was in agreement with obtained by Robinson et al. 1951; Johansson et al., 1955, Sarwar et al.2004, Al-Gubory et al., 2006, Hussin et al. 2010, Dawood et al., 2015 and Sebastia et al., $\quad 2019$

Table (7): Variance components, heritability and genetic advance for characters bread wheat genotype

\begin{tabular}{ccccccccc}
\hline Character & VG & VE & VP & GcV\% & PCV & H\% & GA & GAM\% \\
\hline Plant height & 60.8 & 19.91 & 80.75 & 10.97 & 12.64 & 75.0 & 11.85 & $16.67 \%$ \\
\hline Flag leaf area & 5.42 & 9.45 & 14.87 & 4.83 & 8.00 & 36 & 2.44 & $5.07 \%$ \\
\hline Weight of grain gm & 0.095 & 0.048 & 0.143 & 13.75 & 16.88 & 66 & 0.43 & $0.91 \%$ \\
\hline Number of grain & 53.1 & 14.70 & 67.80 & 13.19 & 14.19 & 78 & 11.30 & $20.47 \%$ \\
\hline 1000-grain wt.grain & 27.88 & 9.70 & 37.58 & 12.90 & 14.98 & 74 & 7.98 & $19.52 \%$ \\
\hline Grain yield & 1586.35 & 1874.56 & 3460.91 & 17.06 & 25.20 & 45 & 46.59 & $19.95 \%$ \\
\hline
\end{tabular}

VG- Variance genotypes, VE- Variance environment, VP- Variance of phenotypic, GcVGenotypic coefficient variance, PCV- Phenotypic coefficient variance, H- Heritability broad sense, GA- Genetic advance, GAM- Genetic advance as mean.

The results in Table 8 and 9. revealed the analysis of variance between the wheat genotypes, the results showed highly significant between the genotypes in the values of selection index for these which computed depend on the better selection index which consist yield, plant height and 1000grain weight. From the results of comparison between the means of genotypes, the highest mean index reached 17.056 for genotype 2 and with out significant with some genotypes and significant with others. Therefore this genotype was the better and followed by genotype (1) and genotype (3) and

Table (8): analysis variance to test significant of selection indices values differences among genotypes.

\begin{tabular}{cccccc}
\hline Source & df & Sum of square & Mean square & F value & Pr. $>$ F \\
\hline Replication & 2 & 227.04 & 113.52 & 2.68 & 0.091 \\
\hline Genotype & 11 & 3191.28 & 290.11 & 6.84 & $<.0001$ \\
\hline Error & 22 & 933.47 & 42.43 & & \\
\hline Total & 35 & 14351.79 & & & \\
\hline
\end{tabular}

Table (9): Analysis variance of index fo each genotype

\begin{tabular}{cccc}
\hline Genotypes & Mean & Genotypes & Mean \\
\hline 1 & $16.36 \mathrm{a}$ & 7 & $-1.75 \mathrm{def}$ \\
\hline 2 & $17.05 \mathrm{a}$ & 8 & $12.90 \mathrm{abc}$ \\
\hline 3 & $13.68 \mathrm{ab}$ & 9 & $-9.69 \mathrm{f}$ \\
\hline 4 & $9.84 \mathrm{abcd}$ & 10 & $9.76 \mathrm{abcd}$ \\
\hline 5 & $1.05 \mathrm{cdef}$ & 11 & $2.69 \mathrm{bcde}$ \\
\hline 6 & $-9.59 \mathrm{f}$ & 12 & $-5.48 \mathrm{fe}$ \\
\hline
\end{tabular}

Finally it was concluded from this study that the better four genotypes respectively was 2,1 , and 3 and surpassed genotype over all genotypes and could be used this genotypes in breeding programs to improved yield of wheat and develop new variety with good productivity and good 
quality performance to Kurdistan and Iraqi environments.

\section{REFERENCES}

Ahmed . A. A. And A. M. Hamdoo. 2000. Heritubil genetic variance coefficient and Relative efficiency for several selection indices in bread wheat. Mesopot. J. Agric.32-103-108.

Al-Gubory. J. M. A, A. H. AL gubory and L. Kh. 2006 several indices in broad wheat. J. Tikrit Univ. Agric. Sci. 6: 54- 65.

Ali. I. H. 1995. Evaluation of relative efficiency of several selection indices for prediction of expected genetic advance in wheat grain yield. Mesopot. J. Agric. 28: 75-79.

Assefa, K, Alema. D, Sheratorik, Kirab A. 2011. Chlenges and opportunities of rice in Ethiopia Agricultural Develoment. Ethiopian Institute of Agricultural Research. Addis Abada, : P: 10.

Dawood S. M. Alobaidy, Jasim M. Ahmad H. AlJaboory. 2015. Estimating of genetic parameters and construction of selection indices for exotican Endogenous maize genotypes. Journal Tikrit. For Agri. Sci. Vol. 15 No.1 .

Bhatnagar. V. K, R. C. Sharma and M.B. Bhatnagar 1982. Selection index in Barely. Crop Sci. Improve. 9: 75-77.

Costal. M. M., Di-Mauro. A. O, Uneda-Trevisoli. SH, Arriel. N. H. C, Barbo. I. M and G. D. Silveira. 2008. Analysis of dried and indirect selection and indices in soybean segregating population. Crop breeding. Appl. Biot. 8: 47-55.

Cotterill. P. P. 1985. on index selection: simple indices which require no genetic parameters of special expertise to construct. Silvae. genet. 34:2-3.

Dawod. K. M. M. A. H. Al- falahy and A. S. A. Mohammad. 2010. Evaluation of introduced bread wheat genotypes through selection index technique.

Gomez. K. A and A. A. Gomez. 1984. Statistical procedures for agricultural Research. 2nd ed, John Wiley and Sons. New York.
Hazel. L. N. 1943. The genetic basis for constructing selection indexes. Genetics. 28- 476- 490.

Hazel. L. N. and J. L. Lsuh. 1942. The efficiency of three methods of selection. J. Hered. 33: 393399.

Hussin, N, M. S. Baloch, Q. Zaman, A. Aziz and S. Sadozi. 2010. Adoptability and genetic variation in some maize hybrids. Journal of Agricultural Research. 48(4): 437-443.

Miller. P.A., J.C. Williams, H.F. Robinson and R.E. Comstock. 1985. Estimation of genotypic and environmental variance and covariance in slelection. Argon.S. Vol. 50. PP 126-131.

Robinson. H. F, R. E. Comstock and P. H. Harvey. 1951. Genotypic and phenotypic correlation in corn and their implication in selection. Argon. J.43, 282-287

Pesek. J. and R. J. Baker. 1969. Desired improvement in relation to selection indices. Can. J. Plant Sci. 49: 803-804.

Sarwar. G, M. S. Sadiq. M. Saleem and G. Abbas. 2004. Selection criteria in F3 and F4 population of mung bean. Pak. J. Bot. 36(2): 297-310.

Sebastia. M., L. Franziska, A. Christan, P. Bernadette, S. Ellen and B. Hermann. 2019 Simultaneous selection for grain yield and protein content in genomics-assistes wheat breeding. Theoretical and applied genetic. 132:1745-1760.

Singh. S. P, P. M. Asaw and N. Singh. 1979. Wheat research station pousar Kedu, JNKVV. Research. V. Bana 1 to 4 January to October pp: 18-19.

Smith. H. F. 1936. A discriminate function of plant selection. Ann. Eugen. 7: 240-250.

Wells. W. C. and K. D. Kofoid. 1986. Selection index to improve an intermitting.

Zine-El, H. Abderrahmane and b. Hamenna.2018. Analysis of direct and indirect selection and indices in bread wheat (Triticum aestivum L.) segregating progeny. International Journal of $\begin{array}{lll}\text { Agronomy } & 3: & 11-19 \text {. }\end{array}$

\section{ههلسهنكاندنا توخميّن ميراتى ز گهنمى نانى بكارئينانا ته كنيكا ريبهرى ههلبزارتنى}




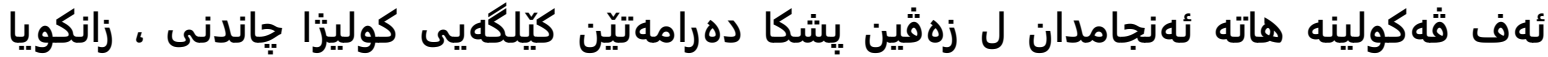

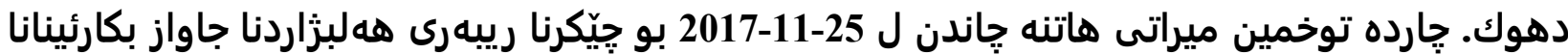

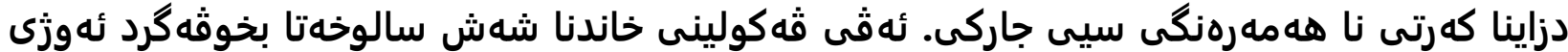

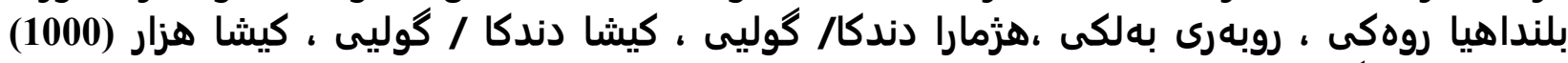

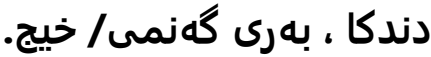

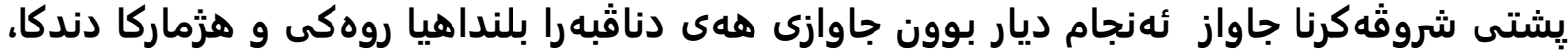

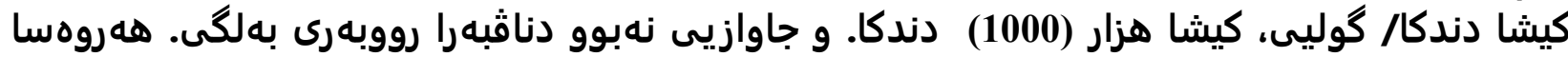

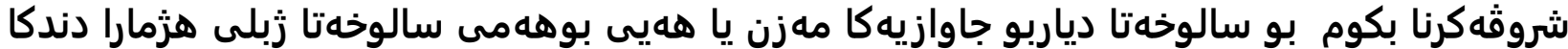

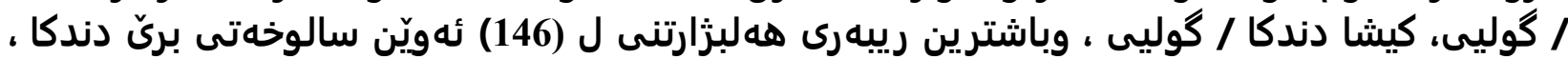

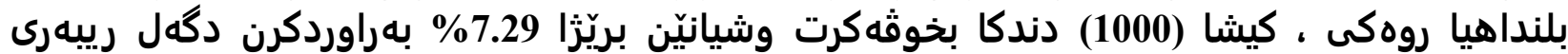

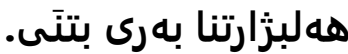

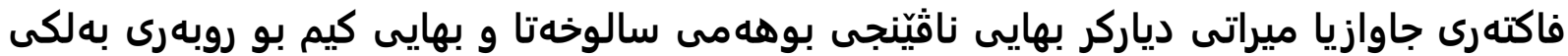

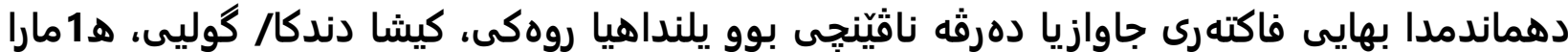

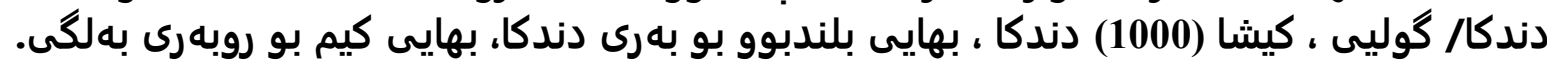

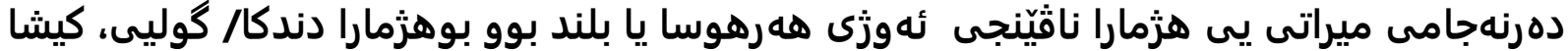

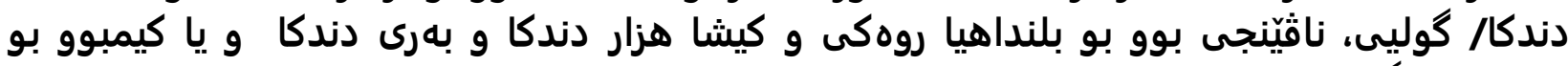

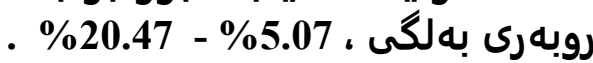

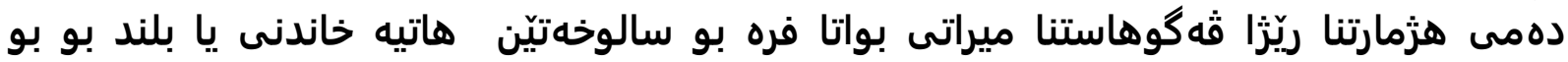

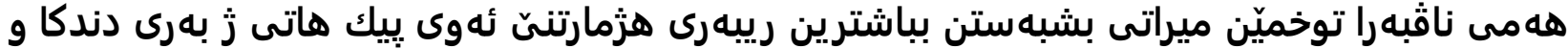

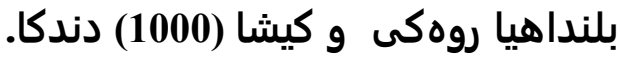

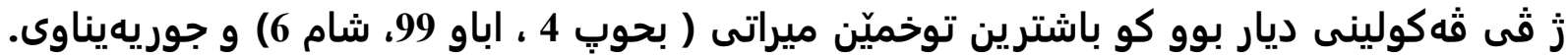

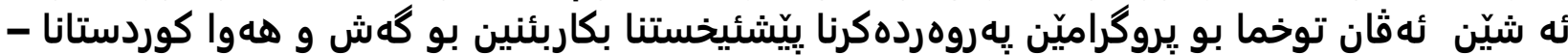
عيراقى.

تقيم تراكيب وراثية من حنطة الخبز باستخدام تقنية دليل الانتخاب

الخلاصة

طبقت تجربة في حقل قسم المحاصيل الحقلية / كلية الزراعة جامعة دهوك. زلقاء العاء اثنا عشر تركيبا

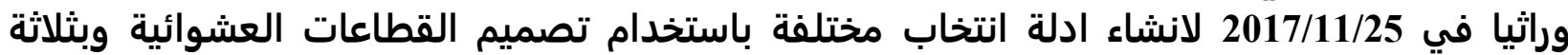

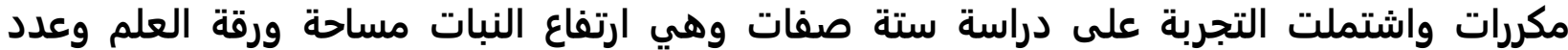
الحبوب في السنبلة ووزن حبوب السنبلة و وزن 1000 حبة وحاصل الحبة الحبوب خط. 
اظهرت نتائج تحليل التباين وجود فروقات معنوية لارتفاع النبات وعدد الحبوب في السنبلة ووزن

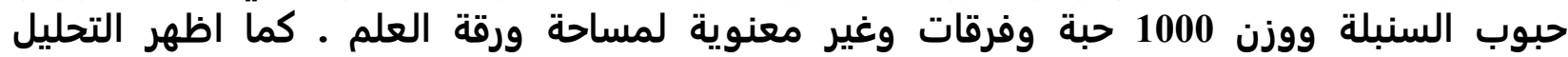

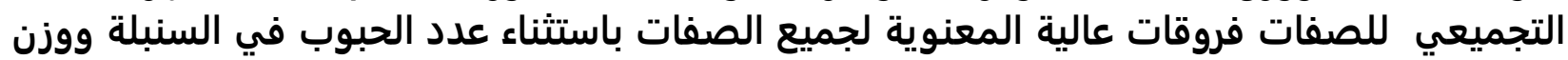

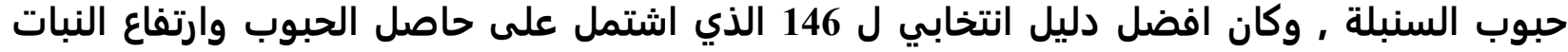

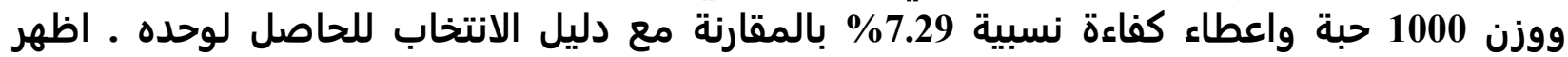

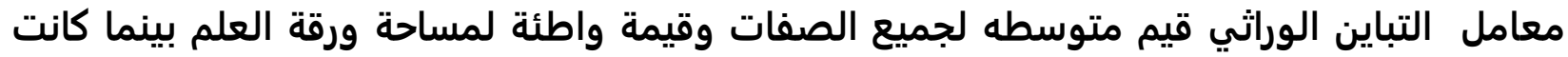

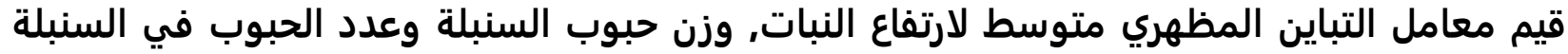

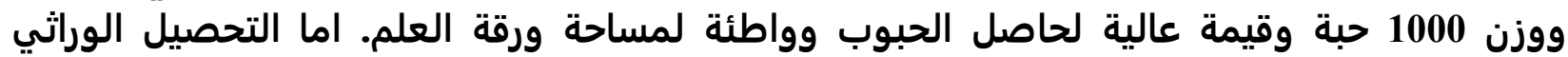

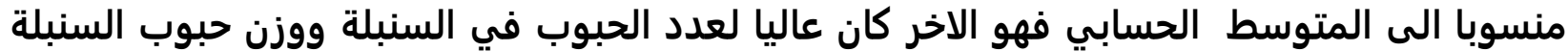

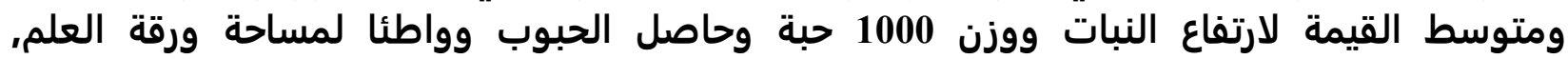

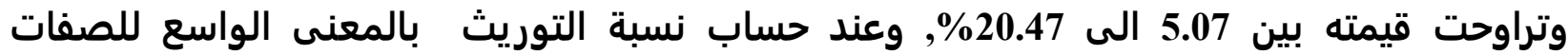

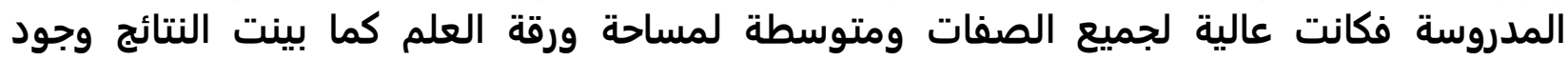

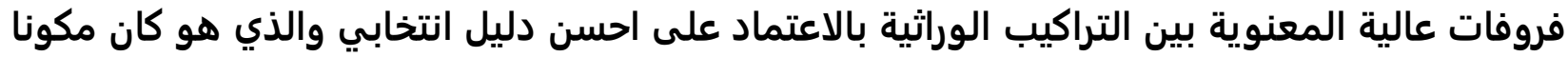

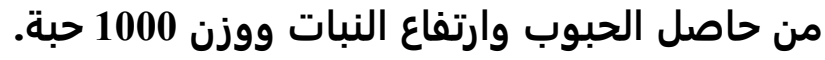

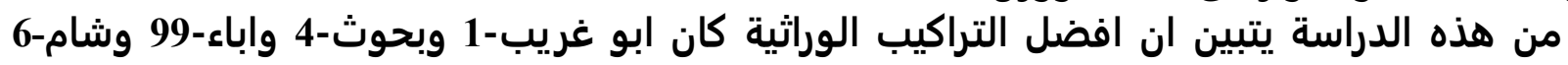

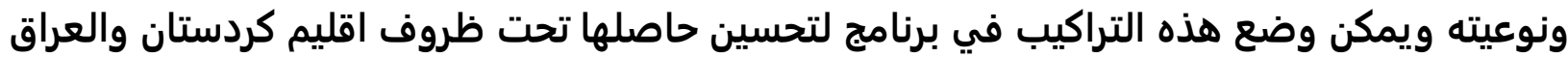

